\title{
Bridging aortic valve surgery to 21st century: what can a surgeon do?
}

\author{
Mizar D’Abramo', Luisa Ferrante ${ }^{2}$, Manuel Guerrera ${ }^{3}$, Wael Saade ${ }^{1}$, Ernesto Greco', Fabio Miraldi', \\ Antonino Marullo ${ }^{4}$, Mariangela Peruzzi ${ }^{4}$, Antonio Barretta ${ }^{5}$, Piero Proietti ${ }^{5}$, Giuseppe Biondi-Zoccai ${ }^{4,6}$, \\ Sebastiano Sciarretta ${ }^{4,6}$, Giacomo Frati ${ }^{4,6}$, Alessandra laccarino $0^{7,8}$
}

\author{
'Department of Cardiovascular, Respiratory, Nephrological, Anesthesiological, and Geriatric Sciences, Sapienza University of \\ Rome, Rome 00100, Italy. \\ 2Division of Cardiac Surgery, San Giovanni Battista Hopital "Molinette", University of Torino, Turin 10126, Italy. \\ ${ }^{3}$ Department of Anesthesiology and Intensive Care Medicine, Fondazione Policlinico Universitario A. Gemelli, Università \\ Cattolica del Sacro Cuore, Rome 00100, Itay \\ ${ }^{4}$ Department of Medico-Surgical Sciences and Biotechnologies, Sapienza University of Rome, Latina 04100, Italy. \\ ${ }^{5}$ DAI Cardio Toraco Vascolare, Chirurgia e Trapianti D'Organo, Policlinico Umberto I, Sapienza University of Rome, Rome 00100, Italy \\ ${ }^{6}$ IRCCS Neuromed, Pozzilli 86077, Italy. \\ 7Department of General and Specialistic Surgery “Paride Stefanini”, Sapienza University of Rome, Rome 00100, Italy. \\ ${ }^{8}$ Department of Cardiac Surgery, Humanitas Clinical and Research Hospital, Rozzano 20089, Italy.
}

Correspondence to: Dr. Alessandra laccarino, Department of General and Specialistic Surgery "Paride Stefanini", Sapienza University of Rome, Rome 00100, Italy. E-mail: dr.alessandra.iaccarino@gmail.com

How to cite this article: D'Abramo M, Ferrante L, Guerrera M, Saade W, Greco E, Miraldi F, Marullo A, Peruzzi M, Barretta A, Proietti P, Biondi-Zoccai G, Sciarretta S, Frati G, laccarino A. Bridging aortic valve surgery to 21st century: what can a surgeon do? Vessel Plus 2019;3:4. http://dx.doi.org/10.20517/2574-1209.2018.41

Received: 1 Jun 2018 First Decision: 7 Sep 2018 Revised: 12 Nov 2018 Accepted: 4 Jan 2019 Published: 24 Feb 2019

Science Editor: Cristiano Spadaccio Copy Editor: Cui Yu Production Editor: Huan-Liang Wu

\begin{abstract}
Aortic valve stenosis is the most clinically relevant valvular heart disease in the elderlies. Surgical aortic valve replacement (SAVR) represented, for decades, the standard of care for the treatment of severe aortic stenosis. Although SAVR still represents a valid option in this clinical scenario, transcatheter aortic valve implantation proved to be superior to medical therapy and comparable to SAVR in several randomized trials in patients at high or intermediate operative risk. At the same time, the growing aging population carrying on greater morbidities and high risk profiles has led to the development of minimally invasive technologies, as rapid deployment aortic valve replacement or Sutureless, to minimize surgical impact on patients. The Heart Team is nowadays tasked to determine the best option tailored for each patient considering patient-related factors and mastering all the surgical options in terms of both different techniques and types of available valves. Nevertheless, some open issues need to be already answered as: which has the longest durability, which the lower complication rate and the lower overall mortality. The aim of this review is to briefly resume
\end{abstract}

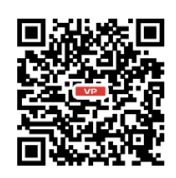


the main features of these different options and explore what kind of open questions these newer-generation prosthetic valves and delivery devices carry.

Keywords: Aortic valve surgery, aortic valve stenosis, cardiac surgery, sutureless, transcatheter aortic valve implantation, newgeneration devices, minimally invasive technologies

\section{INTRODUCTION}

Aortic valve stenosis is the most clinically relevant valvular heart disease in the elderly people with a prevalence of $21 \%-26 \%$ in the elderly above 65 years of age and it increases with age, determining prognosis worsening after symptoms occurrence ${ }^{[1]}$. Surgical aortic valve replacement (SAVR) has represented, for decades, the standard treatment for patients with symptomatic and severe aortic stenosis, resulting in relief of symptoms, in a significant improvement of clinical outcome and in an improved survival. Although SAVR still represents a valid option in the setting of aortic valve stenosis, transcatheter aortic valve implantation (TAVI) proved to be superior to medical therapy and comparable-non inferior to SAVR in several randomized trials as well as in registries ${ }^{[2-4]}$. Following its introduction in 2002, with the first case performed in Rouen by Cribier et al. ${ }^{[2]}$, TAVI has become an established treatment for patients with severe symptomatic aortic stenosis deemed inoperable or at high risk for conventional surgery. About 300,000 procedures have been performed worldwide with the first and second-generation CE-marked devices: Medtronic CoreValve (Medtronic, Minneapolis, MN, USA) and Edwards SAPIEN ${ }^{\mathrm{TM}} /$ SAPIEN XT ${ }^{\mathrm{TM}}$ (Edwards Lifesciences, Irvine, CA, USA) with an annual compound growth rate of $40 \%{ }^{[5]}$. Due to an overall increased experience and the progressing technology in transcatheter valve systems ${ }^{[6]}$, TAVI has been proposed and used in patients who are at intermediate and even low risk. The analysis of the Cohort A of the randomized trial PARTNER 2 showed that TAVR was non-inferior to surgical aortic-valve replacement in terms of primary end-point of death or disabling stroke ${ }^{[7]}$. Therefore, recently published European guidelines ${ }^{[8]}$ has reinforced TAVI recommendation in intermediate risk patients (class Ib, level of evidence B). Moreover the growing aging population, characterized by greater co-morbidities and risk profiles has led to the development of minimally invasive technologies ${ }^{[9]}$ to reduce surgical impact on patients. An increasing number of surgeons are now endorsing minimally invasive aortic valve replacement through the sutureless valve technology (or rapid deployment valve). With this new emerging technology, TAVI, reasonable issues arise in comparison with surgical techniques and need to be answered: (1) which has the longest durability; (2) which encompasses the lower complication rate; and (3) the lower overall mortality.

\section{SURGICAL AND INTERVENTIONAL APPROACHES}

Patients usually can be scheduled to undergo a SAVR through conventional full midline sternotomy or miniaccess according to the surgeon's discretion and/or patients characteristics. In these two settings, patients can receive either a conventional stented or sutureless prosthesis. Compared with conventional surgery, minimally invasive access can provide shorter hospital stay, improve postoperative respiratory function and reduces postoperative pain, blood loss and blood transfusions thanks to the lower invasiveness. Commons minimally invasive approaches are: the partial upper ministernotomy, the right anterior minithoracotomy, the right parasternal approach from the second to the fourth costal space and the transverse sternotomy. Surgical approach, minimally invasive or not, still represents the standard of care for several reasons: it has the longest follow up, it can be performed in younger patients, in patients with intermediate-low risk profile, in patients requiring combined cardiac procedures or a redo operation. Open-heart surgery allows controlled and accurate decalcification of aortic annulus and consequently a safe valve positioning under a direct visualization and with a major leaks control. In specific condition, also an aortic root enlargement can be performed with this approach. On the other hand, standard surgical intervention is a time-consuming procedure in term of cardio-pulmonary bypass (CPB), cross-clamp and myocardial ischemia times. Patients 
at higher risk can easily experience the so-called CPB side effects embracing a sequelae of side effects involving several organs and apparatus ${ }^{[10]}$. Alternative minimally invasive options has led to "sutureless" or rapid deployment aortic valves (RD-AV), which avoid the placement and tying of sutures finally leading to shorter CPB time. Sutureless valves are biological pericardial prostheses that can be anchored to the aortic annulus with only three sutures. Three different prostheses has to date, been developed: $3 \mathrm{~F}$ Enable (Medtronic, Minneapolis, USA - CE approval withdrawn), Perceval S (Sorin, Saluggia, Italy), and Intuity Elite (Edward Lifesciences, Irvine, USA). The 3 F Enable and Perceval S sutureless prostheses have a nitinol metal frame and can be deployed and positioned with no sutures in the case of Perceval S valves and only one suture for the Enable $3 \mathrm{~F}$ valves. The Intuity rapid deployment aortic valve prosthesis has a cloth-covered frame and it is implanted through a balloon catheter delivery system that expands the frame once it achieved the appropriate annular position. Three sutures are required in the case of the Edwards Intuity valve. This technique may lead to shorter cross-clamp and CPB times, with a smaller amount of related adverse side effects, shorter in-hospital stay and similar survival rates as compared with conventional AVR. Actually, the procedure time is operator-dependent and relates to the specific operator learning curve. The prosthesis is usually landed in an intranular position and this may lead to better hemodynamic performance. RD-AV need careful patient selection since they need symmetric sinus configuration for adequate fitting in order to avoid paravalvular leakage and they are not recommended in bicuspid aortic valves. On one hand, it is not recommended to entirely decalcify the aortic annulus since it can be useful for the anchorage and likewise it avoids paravalvular leaks; on the other hand, heavily calcified sinutubular junctions may require special caution in sizing and deployment stages. Risk of stroke still represents an open issue since there are no specific recommendations regarding anticoagulation regimen after RD-AV implantation and no data are available on the risk of thrombus formation because of the stent frame and leaflet designs.

Greater morbidities and high-risk profiles on the contemporary patient population have driven the development of percutaneous TAVI, delivered in a micro-invasive fashion, with no need of CPB neither cardioplegic induced cardiac arrest. TAVI procedures have dramatically increased worldwide even if this data did not result in a decrease of overall SAVR performed compared with prior years ${ }^{[11]}$. This means that a consistent part of patients currently treated with TAVI could not beneficiate any surgical options in the previous years, the so called "pre-TAVI era". Although it proves to be a good and safe technique in patients at intermediate - high risk, there are several factors to consider for eligibility as: (1) native annulus size, since $<18 \mathrm{~mm}$ or $>29 \mathrm{~mm}$ precludes this procedure; (2) cardiac anatomy, necessary in the choice of implant and method of delivery; (3) left ventricular outflow size and shape; (4) porcelain aorta or horizontally placed aortic root, that may complicate a transfemoral delivery; (5) height of coronary artery ostia, to prevent incidental occlusion of the coronaries; (6) assessment of the peripheral arterial vessels, in terms of diameter, tortuosities, kinks, preexisting stents, aneurysms or thrombi.

In this setting, it is clear how an appropriate patient selection is the key of success for a good outcome. Nevertheless, there are still open issues in terms of possible complications that deserve to be considered: (1) risk of malpositioning, since some models can not be repositioned, retrieved or resheathed; (2) risk of annular rupture because of oversizing or over dilatation, even if this is an experience-related complication more than a limit of the technique itself; (3) atrioventricular conduction abnormalities requiring a postoperative permanent pacemaker (PPM), this complication ranges between $3 \%-8 \%{ }^{[11]}$; (4) paravalvular leaks; (5) risk of stroke; (6) vascular and bleeding complications; (7) limited durability.

Due to their multifaceted aspects, requiring several different evaluations by several different professionals, in the last years a new concept has emerged and gained increasing attention in the context of several procedures like complex coronary interventions and TAVR: the Heart Team.

The "Heart Team" should play a pivotal role in decision making, since most procedures entail a complex interplay of multispeciality \& multi modality skills such as in the case of TAVI. The Heart Team is thus 
Table 1. Types of prosthesis available and main features

\begin{tabular}{|c|c|c|c|c|c|c|c|c|c|c|c|}
\hline \multirow[b]{2}{*}{ Models } & \multicolumn{9}{|c|}{ TAVI } & \multicolumn{2}{|c|}{ RD-AVR } \\
\hline & $\begin{array}{l}\text { SAPIEN } \\
\text { XT } \\
\text { Edwards }\end{array}$ & $\begin{array}{l}\text { SAPIEN } \\
3 \\
\text { Edwards }\end{array}$ & $\begin{array}{l}\text { Corevalve } \\
\text { Medtronic }\end{array}$ & $\begin{array}{l}\text { Evolut R } \\
\text { Medtronic }\end{array}$ & $\begin{array}{l}\text { Evolut } \\
\text { PRO } \\
\text { Medtronic }\end{array}$ & $\begin{array}{l}\text { Allegra } \\
\text { NVT }\end{array}$ & $\begin{array}{l}\text { Jena Valve } \\
\text { JenaValveTech }\end{array}$ & $\begin{array}{l}\text { Portico } \\
\text { St Jude } \\
\text { Med }\end{array}$ & $\begin{array}{l}\text { Lotus } \\
\text { Boston } \\
\text { Sc. }\end{array}$ & $\begin{array}{l}\text { Perceval } \\
\text { LivaNova }\end{array}$ & $\begin{array}{l}\text { Intuity } \\
\text { Edwards }\end{array}$ \\
\hline Approach & $\begin{array}{l}\text { Femoral } \\
\text { Trans } \\
\text { apical } \\
\text { Trans } \\
\text { aortic }\end{array}$ & $\begin{array}{l}\text { Femoral } \\
\text { Trans } \\
\text { apical } \\
\text { Trans } \\
\text { aortic }\end{array}$ & $\begin{array}{l}\text { Femoral } \\
\text { Suxlavian/ } \\
\text { axillar } \\
\text { Trans aortic }\end{array}$ & $\begin{array}{l}\text { Femoral } \\
\text { Suxlavian/ } \\
\text { axillar } \\
\text { Trans } \\
\text { aortic }\end{array}$ & $\begin{array}{l}\text { Femoral } \\
\text { Suxlavian/ } \\
\text { axillar } \\
\text { Trans } \\
\text { aortic }\end{array}$ & Femoral & Transapical & Femoral & Femoral & $\begin{array}{l}\text { Trans aortic } \\
\text { (Full } \\
\text { sternotomy } \\
\text { or mini- } \\
\text { invasive } \\
\text { fashion) }\end{array}$ & $\begin{array}{l}\text { Trans aortic } \\
\text { (Full } \\
\text { sternotomy } \\
\text { or mini- } \\
\text { invasive } \\
\text { fashion) }\end{array}$ \\
\hline Introducer & $\begin{array}{l}16,18 \\
20\end{array}$ & $14,16 \mathrm{Fr}$ & $18,20 \mathrm{Fr}$ & $14,16 \mathrm{Fr}$ & $16 \mathrm{Fr}$ & $18 \mathrm{Fr}$ & $32 \mathrm{Fr}$ & $18 \mathrm{Fr}$ & $\begin{array}{l}18,20 \\
\mathrm{Fr}\end{array}$ & -- & -- \\
\hline Deployment & Balloon & Balloon & Self Exp & Self Exp & Self Exp & Self Exp & Self Exp & Self Exp & Balloon & Self Exp & Balloon \\
\hline Valve sizes & $\begin{array}{l}23,26 \\
29\end{array}$ & $\begin{array}{l}23,26 \\
29\end{array}$ & $26,29,31$ & $\begin{array}{l}23,26 \\
29,34\end{array}$ & $23,26,29$ & $\begin{array}{l}23,27 \\
31\end{array}$ & $23,25,27$ & 23,25 & $\begin{array}{l}23,25 \\
27\end{array}$ & $\begin{array}{l}\mathrm{S}, \mathrm{M}, \mathrm{L}, \mathrm{XL} \\
(19-27 \mathrm{~mm})\end{array}$ & $19-27$ \\
\hline Recaptable & No & No & No & Yes & Yes & Yes & No & Yes & Yes & $\begin{array}{l}\text { Yes No } \\
\text { Recommend }\end{array}$ & No \\
\hline $\begin{array}{l}\text { Valve in } \\
\text { valve }\end{array}$ & Yes & Yes & Yes & Yes & Yes & No data & No data & Yes & Yes & -- & -- \\
\hline
\end{tabular}

TAVI: transcatheter aortic valve implantation; RD-AVR: rapid deployment aortic valve replacement

tasked to determine the best option for each patient considering many patient related factors and mastering all the surgical options both in terms of different techniques and types of valves available. Hereafter we offer a summing up table of all the current options as listed below [Table 1].

\section{DISCUSSION}

Conventional surgical treatment of aortic valve stenosis still represents the standard of care that can be performed with excellent outcomes. The growing aging population, the increasing number of comorbidities and the higher score risk of a consistent part of patients have led to the introduction of novel opportunities both as interventional and as surgical approaches [TAVI $v s$. rapid deployment aortic valve replacement (RDAVR)]. The decision to schedule one of these options should be based on a multilevel evaluation that includes the assessment of patients' frailty, anamnesis, anatomy and degree of atherosclerosis of the aorta and peripheral vessels. Data available on prostheses' hemodynamic performance and patients' clinical outcomes play a crucial role in the decision process of both, type of procedure and device selection. Over the latest years, many comparative studies and meta-analysis are emerging on this argument.

Thanks to the analysis of the Cohort A of the randomized trial PARTNER $2^{[7]}$, it is now clear that TAVI procedure is non-inferior to surgical standard aortic valve replacement in terms of primary end-point of death or disabling stroke in intermediate risk patients. In particular, transfemoral TAVI procedure showed less mortality rate than SAVR, compared to transapical TAVI that showed the same mortality rate and the same kind of complications ${ }^{[7,12]}$. Also a previous work of our group showed a similar survival after transcatheter or SAVR ${ }^{[13]}$. Takagi et al. ${ }^{[14]}$ analyzed 8 studies comparing SAVR and TAVI in 4244 patients from 2010 and 2015 and compared results in terms of gained left ventricular ejection fraction (LVEF) and left ventricular mass (LVM). This meta-analysis suggests greater LVM improvement after AVR, which may be due to higher incidence moderate aortic regurgitation after TAVI. LVEF improvement seems to be the same between TAVI and SAVR; but in patients with low baseline LVEF $(<40 \%)$ the improvement may be grater after TAVI than after SAVR. Witberg et al. ${ }^{[15]}$ made a systematic review and meta-analysis on the relative risks and benefits of TAVR $v s$. SAVR in patients who are at low surgical risk. TAVI and SAVR resulted equivalent in short-term mortality but, in intermediate term mortality, TAVI showed increasing mortality rates compared to SAVR suggesting that TAVI should not be performed in this population. The analysis of TAVI in the low surgical risk population (Shot Term Risk Calculator - STS $<4 \%$ ) is currently under evaluation by three randomised controlled trials (RCTs): the PARTNER 3 (NCT02675114), Medtronic 
transcatheter aortic valve replacement in low risk patients (NCT02701283), and NOTION 2 (NCT02825134) trials ${ }^{[16]}$. Tam et al ${ }^{[17]}$ conducted a cost utility analysis comparing TAVI and SAVR in intermediate risk patients with severe aortic stenosis and TAVI appeared to be also a cost - effective treatment not only in terms of absolute value but also in terms of perspective quality of life and re-hospitalization. Villablanca et al. ${ }^{[18]}$ published a meta-analysis on long-term outcomes of TAVR $v$ s. SAVR. Their analysis confirms the findings from RCTs about similar longterm mortality between SAVR and TAVR. TAVR showed higher incidence of PPM implantation, residual aortic regurgitation, and vascular complications; SAVR showed higher incidence of myocardial infarction. Incidence of stroke, atrial fibrillation and acute kidney injury were lower with TAVR, especially in the high-risk population. Lastly the risk of PPM implantation is similar in intermediaterisk patients between both TAVR and SAVR.

Data published on the comparison between RD-AVR and SAVR underline the benefits of RD-AVR in terms of operative time reduction, CBP duration and increased effective orifice area and consequent lower postoperative transvalvular gradient ${ }^{[19]}$. The most common complications reported in the case of RD-AVR are higher incidence of pacemaker implantation, postoperative stroke and residual aortic regurgitation ${ }^{[20]}$, while the most common complications reported in the case of standard procedure tend to be exclusively surgery related as major bleeding or acute renal failure ${ }^{[21]}$. Totally in contrast to these previous studies, the German Aortic Valve Registry (GARY) recently analyzed a total of 22,062 patients who underwent isolated SAVR using SAVR or RD-AVR between 2011 and $2015^{[22]}$. GARY analysis demonstrated that the advantages carried by RD-AVR may not translate into effective benefits. Patients currently undergoing SAVR are at low intermediate surgical risk, with consequent low expected complication rates, so low pacemaker rate is still a strong argument in favor of SAVR. According to the authors, there are no reasons for choosing RD-AVR and increasing the risk of a post-operative PPM implantation. In contrast to the previous studies, this analysis also showed significantly elevated post-operative transvalvular gradients in sutureless valves, independently of the implanted valve sizes. At last, many data exist regarding comparison between RD-AVR and TAVI even if they do not always stratify patients for surgical scoring risk, in consequence TAVI patients tend to have higher scores. Meco et al. ${ }^{[23]}$ made a metanalysis of 6 studies including 1,462 patients (RD-AVR 731 vs. TAVI 731) with similar operative risk (Euroscore1: $15.45 \pm 9$ RD-AVR vs. $15.58 \pm 8.1$ TAVI). Thirty days all cause mortality and complications as stroke, paravalvular regurgitation, vascular complications were significantly lower in RD-AVR. The rate of acute kidney injury and pacemaker implantation were similar. RD-AVR group required more transfusion. Mid term survival rates (at 1 or 2 years) were significantly better in RD-AVR. SAVR using sutureless valves may be associated with better early and mid-term outcomes compared with TAVI in high- or intermediate-risk patients; the authors found a 50\% risk reduction in early all causes of death and a $65 \%$ and $62 \%$ risk reduction in 1- and 2-year mortality for TAVI ${ }^{[23]}$. Recently Shinn et al. ${ }^{[24]}$ provided a meta analysis including 7 observational studies comprising 617 RD-AVR and 621 TAVI patients: early mortality was $2.5 \%$ and $5 \%$ respectively, post procedural paravalvular leak was lower in RD-AVR and post procedural stroke and need for pacemaker implantation were comparable between the two cohorts.

From several studies, it appears that post operative need for pacemaker implantation is similar in both techniques, TAVI seems to have lower transvalvular gradients but more common peri-prosthetic leaks and, in the end, RD-AVR seems to have lower mortality rates ${ }^{[25]}$. Finally, a large study from D'onofrio et al. ${ }^{[26]}$ obseverd 2,177 patients (1,885 TAVI vs. 292 RD-AVR): they found similar incidence of 30-day and 1 year mortality rates, stroke, bleeding and myocardial infarction. Patients treated with TAVI showed less device success and more postoperative perivalvular leak, even if this was less evident in trans apical procedures. RD-AVR resulted in higher transaortic gradients, longer post operative length and similar pacemaker implantation rate ${ }^{[26]}$.

\section{CONCLUSION}

The Heart Team is nowadays tasked to determine the best option for each patient considering patient related factors and cost effectiveness. The choice between surgical AVR vs. TAVR is based on multiple factors 
including the surgical risk, patient frailty, comorbidities and also patient preferences. Since 2012, TAVR indications have been extended into groups of patients who are at intermediate to high risk; TAVR has also become the alternative to reoperation for those with bioprosthetic aortic valve degeneration. There are still few data on TAVI for patients $<75$ years of age and for surgical low-risk patients, in whom SAVR remains the preferred approach since long-term durability data for TAVI prosthetic valves are still lacking. Moreover, younger patients often carry a bicuspid valve disease and this anatomic pattern may affect the results of TAVI. The past above cited trials excluded bicuspid valve patients. Surgical approach still plays a crucial role in all the combined procedures as concomitant severe coronary artery disease, concomitant ascending aorta disease or concomitant mitral and tricuspid valve disease. On the other side, longer follow up for both TAVI and RD-AVR are going to be needed, not only for the effective durability, but to clear risk of paravalvular leaks and pacemaker requirement, since they are likely to have greatest impact on low-risk and younger populations on life expectancy and they are currently being investigated in randomized trials. Another open issue is represented by anticoagulation regimen, since no specific recommendations exist on it and no data are available on the risk of thrombus formation because of the stent frame and leaflet designs.

In the end, the approval of a TAVR valve for lower STS SAVR risk population does not mean, by now, that TAVR is going to be the chosen procedure for any patient but this would certainly promote and encourage the scientific debate and future researches.

\section{DECLARATIONS}

Authors' contributions

All authors contributed equally.

\section{Availability of data and materials}

Not applicable.

\section{Financial support and sponsorship}

None.

\section{Conflicts of interest}

All authors declared that there are no conflicts of interest.

\section{Ethical approval and consent to participate}

Not applicable.

\section{Consent for publication}

Not applicable.

\section{Copyright}

(c) The Author(s) 2019.

\section{REFERENCES}

1. Bonow RO, Greenland P. Population-wide trends in aortic stenosis incidence and outcomes. Circulation 2015;131:969-71.

2. Cribier A, Eltchaninoff H, Bash A, Borenstein N, Tron C, et al. Percutaneous transcatheter implantation of an aortica valve prosthesis for calcific aortic stenosis: first human case description. Circulation 2002;106:3006-8.

3. Gilard M, Eltchaninoff H, Iung B, Donzeau-Gouge P, Chevreul K, et al. Registry of trancatheter aortic valve implantation in high-risk patients. N Eng J Med 2012;366:1705-15.

4. Thomas M, Schymik G, Walther T, Himbert D, Lefèvre T, et al. Thirty-day results of the SAPIEN aortic Bioprosthesis European Outcome (SOURCE) Registry. A European registry of transcatheter aortic valve implantation using the Edwards SAPIEN valve. Circulation 2010;122:62-9. 
5. Cribier A. Commemorating the 15-year anniversary of TAVI: insights into the early stages of development, from concept to human application, and perspectives. EuroIntervention 2017;13:29-37.

6. Gatto L, Biondi-Zoccai G, Romagnoli E, Frati G, Prati F, et al. New-generation devices for transcatheter aortic valve implantation. Minerva Cardioangiol 2018;66:747-61.

7. Leon MB, Smith CR, Mack MJ, Makkar RR, Svensson LG, et al. Transcatheter or surgical aortic-valve replacement in intermediate-risk patients. N Eng J Med 2016;374:1609-20.

8. Baumgartner H, Falk V, Bax JJ, De Bonis M, Hamm C, et al. 2017 ESC/EACTS Guidelines for the management of valvular heart disease. Eur Heart J 2017;38:2739-91.

9. Chirichilli I, D’Ascoli R, Rose D, Frati G, Greco E. Port Access (Thru-Port System) video-assisted mitral valve surgery. J Thorac Dis 2013;5 Suppl 6:S680-5.

10. Biondi-Zoccai G, Mancone M, Frati G. Our preoccupation with renal artery disease in patients undergoing cardiac surgery: much ado about nothing? J Am Coll Cardiol 2014;63:317-20.

11. Hamm CW, Arsalan M, Mack MJ. The future of transcatheter aortic valve implantation. Eur Heart J 2016;37:803-10.

12. Ando T, Takagi H, Grines CL. Transfemoral, transapical and transcatheter aortic valve implantation and surgica aortic valve replacement: a meta analysis $\mathrm{f}$ direct and adjusted indirect comparisons of early and mid term deaths. Interact Cardiovasc Thorac Surg 2017;25:484-92.

13. Biondi-Zoccai G, Peruzzi M, Abbate A, Gertz ZM, Benedetto U, et al. Network meta-analysis on the comparative effectiveness and safety of transcatheter aortic valve implantation with CoreValve or Sapien devices versus surgical replacement. Heart Lung Vessel 2014;6:232-43.

14. Takagi H, Ando T, Umemoto T; ALICE (All-Literature Investigation of Cardiovascular Evidence) Group. A meta-analysis of effects of transcatheter versus surgical aortic valve replacement on left ventricualr ejection fraction and mass. Int J Cardiol 2017;238:31-6.

15. Witberg G, Lador A, Yahav D, Kornowski R. Transcatheter versus surgical aortic valve replacement in patients at low surgical risk: a meta-analysis of randomized trials and propensity score matched observational studies. Catheter Cardiovasc Interv 2018;92:408-16.

16. Leipsic J, Bax JJ, Webb JG, Martin R, Blanke P. Trials testing the value of imaging use in valve disease and in transcatheter valvular interventions. JACC Cardiovasc Imaging 2017;10:286-95.

17. Tam DY, Hughes A, Fremes SE, Youn S, Hancock-Howard RL, et al. A cost-utility analysis of transcatheter versus surgical aorticvalve replacement for the treatment of aortic stenosis in the population with intermediate surgical risk. J Thorac Cardiovasc Surg 2018;155:1978-88.

18. Villablanca PA, Mathew V, Thourani VH, Rodés-Cabau J, Bangalore S, et al. A meta-analysis and meta-regression of long-term outcomes of transcatheter versus surgical aortic valve replacement for severe aortic stenosis. Int J Cardiol 2016;225:234-43.

19. Rahmanian PB, Kaya S, Eghbalzadeh K, Menghesha H, Madershahian N, et al. Rapid deployment aortic valve replacement: excellent results and increased effective orifice areas. Ann Thorac Surg 2018;105:24-30.

20. Hurley ET, O'Sullivan KE, Segurado R, Hurley JP. A meta-analysis examining differences in short-term outcomes between sutureless and conventional aortic valve prostheses. Innovations (Phila) 2015;10:375-82.

21. Ferrari E, Roduit C, Salamin P, Caporali E, Demertzis S, et al. Rapid-deployment aortic valve replacement versus standard bioprosthesis implantation. J Card Surg 2017;32:322-7.

22. Ensminger S, Fujita B, Bauer T, Möllmann H, Beckmann A, et al. Rapid deployment versus conventional bioprosthetic valve replacement for aortic stenosis. J Am Coll Cardiol 2018;71:1417-28.

23. Meco M, Miceli A, Montisci A, Donatelli F, Cirri S, et al. Sutureless aortic valve replacement versus transcatheter aortic valve implantation: a meta-analysis of comparative matched studies using propensity score matching. Interact Cardiovasc Thorac Surg 2018;26:202-9.

24. Shinn SH, Altarabsheh SE, Deo SV, Sabik JH, Markowitz AH, et al. A systematic review and meta analysis of suturless aortic valve replacement versus transcatheter aortic valve implantation. Ann Thorac Surg 2018;106:924-9

25. Takagi H, Ando T, Umemoto T; ALICE (All-Literature Investigation of Cardiovascular Evidence) Group. Direct and adjusted indirect comparisons of perioperative mortality after sutureless or rapid-deployment aortic valve replacement versus transcatheter aortic valve implantation. Int J Cardiol 2017;228:327-34.

26. D’Onofrio A, Salizzoni S, Rubino AS, Besola L, Filippini C, et al. The rise of new technologies for aortic valve stenosis: a comparison of sutureless and transcatheter aortic valve implantation. J Thorac Cardiovasc Surg 2016;152:99-109. 